\title{
Roles of $\mathrm{p38}$ and JNK protein kinase pathways activated by compound cantharidin capsules containing serum on proliferation inhibition and apoptosis of human gastric cancer cell line
}

\author{
YONGHAO SUN ${ }^{1}$, DEJUAN ZHANG ${ }^{2}$, MAO MAO ${ }^{1}$, YANGPING LU ${ }^{1}$ and NING JIAO ${ }^{1}$ \\ ${ }^{1}$ Department of Internal Medicine; ${ }^{2}$ Clinical Medical Research Laboratory, \\ Zibo City Hospital of Traditional Chinese Medicine, Zibo, Shandong 255300, P.R. China
}

Received April 1, 2016; Accepted March 24, 2017

DOI: $10.3892 /$ etm.2017.4704

\begin{abstract}
The aim of the present study was to investigate the inhibitory effect of compound cantharides capsules (CCCs) on the viability and apoptosis of human gastric cancer cell lines, BGC-823 and SGC-7901, and to detect its regulation of gene expression levels, as well as its inhibition mechanisms. Each cell line was grouped into a control group, CCC serum group, 5-fluorouracil (5-FU) group, combination therapy group (CCC serum +5-FU) and serum control group. Growth curves were measured and flow cytometry was used to detect cell apoptosis and cell viability. The mRNA expression level of proliferation-related C-MYC and p53 genes were assayed by reverse transcription-quantitative polymerase chain reaction. Protein phosphorylation levels of proliferating cell nuclear antigen, p38 mitogen-activated protein kinase, extracellular signal-related kinase $1 / 2$, c-Jun $\mathrm{N}$-terminal kinase $(\mathrm{JNK})$ and $\mathrm{I} \kappa \mathrm{B}$ were assayed by western blotting. The combined CCC serum and 5-FU group exhibited a higher inhibition rate in both cell lines and CCC serum therapy demonstrated a similar effect to 5-FU treatment, as demonstrated in the MTT and cell growth assay. Combined therapy significantly decreased the C-MYC mRNA expression levels and increased p53 mRNA expression levels $(\mathrm{P}<0.05)$. Combined therapy of 5-FU and $\mathrm{CCC}$ was more significant compared with CCC serum or 5-FU only $(\mathrm{P}<0.05)$. P38 and JNK-related protein phosphorylation are involved in apoptosis initiated by CCC combined 5-FU therapy. Combined
\end{abstract}

Correspondence to: Dr Yonghao Sun, Department of Internal Medicine, Zibo City Hospital of Traditional Chinese Medicine, 75 Xinjian Road, Zibo, Shandong 255300, P.R. China

E-mail: sunyonghao0201@163.com

Abbreviations: CCC, compound cantharides capsules; 5-FU, 5-fluorouracil; TCM, Traditional Chinese Medicine; MAPK, mitogen-activated protein kinases

Key words: cantharidin, 5-fluorouracil, gastric cancer cell, p38, c-Jun N-terminal kinase, viability therapy was able to significantly inhibit human gastric cancer cell growth $(\mathrm{P}<0.05)$, and advance cell apoptosis compared with CCC serum only. CCC serum resulted in downregulation of the c-Myc gene and upregulation of the p53 gene.p38 and JNK-related protein phosphorylation is involved in the inhibition of cell viability and apoptosis of human gastric cancer cell lines.

\section{Introduction}

In the last 5 years, gastric cancer has become the most frequent cause of cancer-related fatality, making it the fifth most common cancer in the world, with approximately 952,000 new cases diagnosed in 2012 (1,2). In China, gastric cancer is one of the most common cancers and the incidence ranks third among all malignant tumors, after lung and liver cancer in men and after breast and lung cancer in women (3). Despite the fact that diagnostic and therapeutic approaches have advanced in the past decade, the prognosis is still unclear due to the high recurrence (4).

5-fluorouracil (5-FU) is a chemotherapeutic agent that is currently the most widely used drug choice for the treatment of solid tumors, such as metastatic colorectal cancer and gastric cancer (5-8). Alternatively, Traditional Chinese Medicine (TCM) is a multi-channel, multi-layer and multi-target method for treating cancer as an alternative to surgery, radiotherapy, chemotherapy and biological therapy (9). TCM involves the use of complicated ingredients that may promote the inhibition and apoptosis of cancer cells (9). Compound cantharides capsules (CCC) are one of the most common TCMs that contain cantharidin, bear gallbladder powder, Panax ginseng, Astragalus mongholicus root, Eleutherococcus senticosus, as well as other ingredients (10). Clinically, CCC have been used to treat primary liver cancer, lung cancer, rectal cancer and malignant lymphoma (11). Some of the ingredients have been demonstrated to have direct effects on tumor cells. For example, ginsenoside and ginseng polysacchride have been demonstrated to directly inhibit tumor cells (12). Research has indicated that Eleutherococcus senticosus is able to induce apoptosis in human gastric cells (13). Clinically, various TCMs, including CCC, are used in combined therapy to strengthen chemotherapy effects (14). 
Multiple factors are involved in gastric cancer pathogenesis, including tumor suppressor genes, oncogenes and growth factors (15-17). Thus, advanced understanding of the molecular mechanisms involved in gastric cancer therapy is of great clinical significance.

Apoptosis is a genetically controlled process. Cantharidin has been indicated to induce apoptosis via cytochrome $c$ release in a pancreatic $\beta$ cell line (18) and has been demonstrated to have a role in the cell cycle and growth $(19,20)$. Cytochrome $\mathrm{c}$ release and caspase activation are mediated by the translocation of cytosolic B-cell lymphoma-2 associated $\mathrm{X}$ protein to the mitochondria in response to various apoptotic stimuli, which is regulated by a tumor suppressor protein, p53 (21-23). The p53 protein has been well-acknowledged to regulate cellular response to various cellular stresses during cancer progression (24). p53 phosphorylation is mediated by protein kinases, such as extracellular signal-regulated kinase (ERK)-1/2, p38 kinase and c-Jun N-terminal kinase (JNK) by mitogen-activated protein kinases (MAPKs) (25). Dual phosphorylation of threonine and tyrosine within the motif Thr-Glu-Tyr in ERK, Thr-Gly-Tyr in p38 or Thr-Pro-Tyr in JNK induces MAPK activation of the protein kinases (26). Genotoxic agents and apoptosis regulate the p38 and JNK pathways $(27,28)$. Controversial evidence has indicated that the complex roles of different pathways exist and interact to perform distinct cellular effects in various cell lineages $(29,30)$.

In the present study, the aim was to explore whether CCC was able to facilitate 5-FU chemotherapy in human gastric cancer cells by altering cell viability and apoptosis, and to evaluate the mRNA expression levels of proliferation-related genes using reverse transcription-quantitative polymerase chain reaction (RT-qPCR) analysis to determine the differential mRNA expression levels of specific markers. Furthermore, the present study explored the potential effects of combined therapy treatment on cancer cells and findings suggested that combined therapy promoted the inhibition of gastric cancer cell viability through inhibiting JNK and p38 phosphorylation.

\section{Materials and methods}

Serum preparation. In the present study, 20 male Sprague Dawley (SD) rats at 6 weeks and weighing 180-220 g were randomized into a CCC group and a control group for serum collection. Animals were maintained on in a 12-h light/dark cycle at $22^{\circ} \mathrm{C}$ with $55 \%$ humidity and had ad libitum access to food and water. The present study was approved by the Ethics Committee of Zibo City Hospital of Traditional Chinese Medicine (Zibo, China). CCC was purchased from Huaxi Pharmaceutical Co., Ltd. (Baoji, China). In the CCC group, CCC was administered intragastrically to SD rats. In human patients, $4.5 \mathrm{~g}$ medication is given to adults with an average weight of $65 \mathrm{~kg} \mathrm{(31).} \mathrm{As} \mathrm{the} \mathrm{average} \mathrm{weight} \mathrm{of} \mathrm{rats} \mathrm{was} 200 \mathrm{~g}$, medication conversion rate was 6.25 . Therefore, 10 rats in the CCC group received a total CCC dosage of $5.4 \mathrm{~g}$ over the course of 5 days. In the first 3 days of the experiment, $2 \mathrm{mg} / \mathrm{ml}$ was administered twice a day to the rats. On days 4 and 5 , rats received $4 \mathrm{ml}(2 \mathrm{mg} / \mathrm{ml}) \mathrm{CCC}$, followed by blood sampling from the femoral artery. The same dosage and same frequency of saline was administered to rats in the control group $(n=10)$.
A total of $2 \mathrm{ml}$ of CCC serum or control serum was taken from each SD male rat for the following experiments.

Cell culture. Human gastric cancer cell lines, BGC-823 and SGC-7901, which are low- and mid-level differentiated, respectively, were purchased from the Cell Bank of the Chinese Academy of Sciences (Shanghai, China) and cultured in RPMI-1640 (Gibco; Thermo Fisher Scientific, Inc., Waltham, MA, USA) supplemented with $10 \%$ fetal bovine serum (FBS; Invitrogen; Thermo Fisher Scientific, Inc.) and $50 \mathrm{U} / \mathrm{ml}$ penicillin and $50 \mu \mathrm{g} / \mathrm{ml}$ streptomycin. Cell culture was maintained at $37^{\circ} \mathrm{C}$ in a humidified atmosphere containing $5 \% \mathrm{CO}_{2}$ prior to switching to a different concentration of CCC serum or control serum for the cell treatment. Each cell line was divided into five groups for treatment: The CCC serum group; $10 \mu \mathrm{l} / \mathrm{ml}$ 5-FU group (Sigma-Aldrich; Merck KGaA, Darmstadt, Germany); CCC serum $+10 \mu \mathrm{l} / \mathrm{ml}$ 5-FU; control serum; and control cells without treatment. Each group included the following subgroups: $5 \% \mathrm{CCC}$ serum, $10 \% \mathrm{CCC}$ serum and $20 \%$ CCC serum subgroup in the CCC serum group; $5 \%$ CCC serum with $10 \mu \mathrm{l} / \mathrm{ml} 5$-FU, $10 \%$ CCC serum with $10 \mu \mathrm{l} / \mathrm{ml}$ 5-FU and 20\% CCC serum with $10 \mu \mathrm{l} / \mathrm{ml} 5$-FU subgroup in the CCC serum $+10 \mu \mathrm{l} / \mathrm{ml} 5$-FU group; and 5\% control serum, $10 \%$ control serum and $20 \%$ control serum subgroup in the control serum group. In each cell line, $24 \mathrm{~h}$ after treatment, cells from each group were transferred to normal RPMI-1640 supplemented with $10 \% \mathrm{FBS}, 50 \mathrm{U} / \mathrm{ml}$ penicillin and $50 \mu \mathrm{g} / \mathrm{ml}$ streptomycin.

CCC treatment, cell viability assay and concentration gradient infection rate. The effect of CCC serum and/or combined therapy on the cell viability of gastric cancer cells was evaluated by MTT assays. BGC-823 and SGC-7901 cells were seeded into 96-well culture plates at a density of $10^{5}$ cells/well in quintuplicate. Serum treatment subgroups from all groups were added to the plates to a concentration of $0.01 \%$ and allowed to adhere for $24 \mathrm{~h}$ before being transferred to normal cell culture (RPMI 1640 supplemented with 10\% FBS, $50 \mathrm{U} / \mathrm{ml}$ penicillin and $50 \mu \mathrm{g} / \mathrm{ml}$ streptomycin). Following incubation at $25^{\circ} \mathrm{C}$ for $30 \mathrm{~min}, 10 \mu \mathrm{l}$ MTT (5 mg/ml; Sigma-Aldrich; Merck KGaA, Darmstadt, Germany) was added to each well for 24,48 or $72 \mathrm{~h}$, after switching back to cell culture, and cells were incubated at $25^{\circ} \mathrm{C}$ for a further $4 \mathrm{~h}$. Media was then removed and $150 \mu 1$ dimethyl sulfoxide (Sigma-Aldrich; Merck KGaA) was then added. After incubation at $37^{\circ} \mathrm{C}$ for $30 \mathrm{~min}$, absorbance (A) was measured at 570 and $630 \mathrm{~nm}$ using a microplate reader (BioTek Instruments, Inc., Winooski, VT, USA) for obtaining optical density (OD) values. Relative cell viability (\%) was calculated using the following equation: Relative viability rate $(\%)=\left(\mathrm{A}_{570 \mathrm{~nm}}-\mathrm{A}_{630 \mathrm{~nm}}\right)$ of study group $/\left(\mathrm{A}_{570 \mathrm{~nm}}-\mathrm{A}_{630 \mathrm{~nm}}\right)$ of control group $x 100 \%$. The optimal incubation time was determined and used for subsequent analysis.

Time gradient infection rate. Each cell line was divided into the control, CCC serum (concentration selected from previous experiment), 5-FU, combined treatment (concentration selected from previous experiment) and serum control groups. Cells $\left(2 \times 10^{5}\right.$ cells $\left./ \mathrm{ml}\right)$ were cultured in RPMI-1640 supplemented with $10 \% \mathrm{FBS}, 50 \mathrm{U} / \mathrm{ml}$ of penicillin and $50 \mu \mathrm{g} / \mathrm{ml}$ of streptomycin at $37^{\circ} \mathrm{C}$ and the appropriate treatment sera were added 
to the cultures of the various group. A total of 24,48 and $72 \mathrm{~h}$ after treatment, cells were transferred to normal cell culture for $4 \mathrm{~h}$ prior to MTT assay for calculating the inhibition rate. The percentage of inhibition was calculated as follows: Inhibition ratio $=(1-\mathrm{OD}$ of study group/OD of control group $) \times 100 \%$. The optimal CCC concentration was determined and used for subsequent analysis.

Cell growth curve. Each cell line was divided into the control, CCC serum, 5-FU, combined treatment and serum control groups. In each group, cells were cultured into a 96-well plate at a density of $10^{5}$ cells/well. A total of $10 \mu \mathrm{l}$ of MTT $(5 \mathrm{mg} / \mathrm{ml})$ was added to each well, after serum incubation, the cells were incubated for 24,48 or $72 \mathrm{~h}$ at $37^{\circ} \mathrm{C}$, respectively. Cells were incubated at $25^{\circ} \mathrm{C}$ for a further $4 \mathrm{~h}$, cell number was subsequently calculated using a hemocytometer and a microscope (Olympus, Tokyo, Japan) and cell growth curves were analyzed.

Apoptosis assays by flow cytometry. Each cell line was divided into control, CCC serum, 5-FU, combined treatment and serum control groups for different treatments. In each group, cells were plated in 6-well culture plates at density of $3 \times 10^{6}$ cells/well. After treatment with different conditions, the cell culture medium was removed and the cells were fixed using $0.5 \mathrm{ml}$ stationary liquid (Beijing Dingguo Changsheng Biotechnology Co., Ltd., Beijing, China) for $10 \mathrm{~min}$. Following the removal of stationary liquid, the cells were pre-incubated with the different serum treatments for $24 \mathrm{~h}$ before they were harvested by centrifugation at $6,000 \mathrm{x}$ g for $20 \mathrm{~min}$ at $4^{\circ} \mathrm{C}$ and washed twice with PBS ( $\mathrm{pH}=7.4)$. Cells were re-suspended in a $2 \times 10^{6}$ cells $/ \mathrm{ml}$ concentration. A total of $1 \mathrm{ml}$ of the cells were transferred into a $15-\mathrm{ml}$ polypropylene tube on ice and $3 \mathrm{ml}$ cold absolute ethanol was added. The cells were incubated for at least $1 \mathrm{~h}$ at $4^{\circ} \mathrm{C}$ for fixation. Subsequently cells were washed twice with PBS and $1 \mathrm{ml}$ propidium iodide (PI; $40 \mu \mathrm{g} / \mathrm{ml}$ ) staining solution was added to the cell pellets and mixed well. Apoptosis of cells was analyzed using FACScalbur flow cytometry (BD Biosciences, San Jose, CA, USA) according to manufacturer's protocol.

Cell cycle detection by flow cytometry. Each cell line was divided into control, CCC serum, 5-FU, combined treatment and serum control groups for different treatments. In each group, cells were plated in 6-well culture plates at a density of $3 \times 10^{6}$ cells/well. Cells were pre-incubated with the different serum treatment for $24 \mathrm{~h}$ before they were harvested by centrifugation at $6,000 \mathrm{x}$ for $20 \mathrm{~min}$ at $4^{\circ} \mathrm{C}$ and washed twice with PBS ( $\mathrm{pH}=7.4)$. The cell solution was then stained using a cell cycle kit (cat. no. YN-28; Forevergen Biosciences Co., Ltd., Guangzhou, China), according to the protocol of the manufacturer. Flow cytometry was performed using a BD FASAria Cell Sorter (BD Biosciences).

Western blot analysis to identify expression levels of key proteins from different signaling pathways. BGC-823 and SGC-7901 cell lines were grown on 6-well culture plates at a density of $3 \times 10^{6}$ cells/well. After $24 \mathrm{~h}$ of treatment, cells from the control, CCC serum, 5-FU, combined treatment and serum control group, were obtained for protein extraction with cold radioimmunoprecipitation assay buffer $(50 \mathrm{mM}$ Tris $\mathrm{pH} 7.4$,
$150 \mathrm{mM} \mathrm{NaCl}, 1 \%$ triton $\mathrm{X}-100,0.1 \%$ SDS, $1 \%$ sodium deoxycholate, $5 \mathrm{mM}$ EDTA, $30 \mathrm{mM} \mathrm{Na}{ }_{2} \mathrm{HPO}_{4}$ and $50 \mathrm{mM} \mathrm{NaF}$ ). Cells were immediately scraped off followed by centrifugation at $12,000 \mathrm{x} \mathrm{g}$ for $15 \mathrm{~min}$ at $4^{\circ} \mathrm{C}$. The supernatants were collected and protein concentrations were determined using Bradford reagent (Bio-Rad Laboratories, Inc., Hercules, CA, USA) by measuring absorbance at $595 \mathrm{~nm}$. A total of $2 \mu \mathrm{g}$ of protein was loaded and separated using $12.5 \%$ SDS-PAGE with a total volume of $20 \mu \mathrm{l} /$ well. The protein from the acrylamide gel was transferred to a nitrocellulose membrane. The membrane was blocked with skimmed milk in Tris-buffered saline-Tween 20 at $4^{\circ} \mathrm{C}$ overnight and subsequently incubated with primary antibodies, including anti-proliferating cell nuclear antigen (PCNA; 1:500; sc25280; Santa Cruz Biotechnology, Inc., Dallas, TX, USA), phosphorylated (p)-P38 (1:500; sc7973; Santa Cruz Biotechnology, Inc.), P38 (1:1,000; cst74451), p-ERK1/2 (1:2,000; cst9106), ERK1/2 (1:1,000; cst4695), p-JNK (1:750; cst4668), JNK (1:1,000; cst9258; all CST Biological Reagents Co., Ltd., Shanghai, China), p-IкB $\alpha$ (1:500; sc8404; Santa Cruz Biotechnology, Inc.) and I $\mathrm{B} \alpha(1: 1,000$; cst4814; CST Biological Reagents Co., Ltd.) overnight at room temperature. Subsequently, blots were incubated with secondary antibody horseradish peroxidase (1:4,000; SRE0082; Sigma-Aldrich; Merck KGaA) for $1 \mathrm{~h}$ at room temperature and washed again as described above. Band intensity was determined using chemiluminescent reagents (Pierce; Thermo Fisher Scientific, Inc., Waltham, MA, USA) and analyzed using ImageJ software v.14.8 (National Institutes of Health, Bethesda, MD, USA).

RT-qPCR analysis. Total RNA was extracted from each of the control, CCC serum, 5-FU, combined treatment and serum control groups in the two cell lines at $24 \mathrm{~h}$ post treatment for the detection of the c-Myc and p53 genes using TRIzol (Takara Bio, Inc., Otsu, Japan). The quantity and purity of RNA were determined by OD measurements at OD A260/A280 ratio with 1.8 or above using Nanodrop 2000 spectrophotometer (Thermo Fisher Scientific Inc.). The cDNA was synthesized from $1 \mu \mathrm{g}$ RNA using a 5 Prime Masterscript RT-PCR System (5 Prime, Inc., Gaithersburg, MD, USA), according to the manufacturer's instructions, and stored at $-20^{\circ} \mathrm{C}$ until assay. The KAPA SYBR FAST qPCR kit (Kapa Biosystems, Woburn, MA, USA) was used for qPCR. The $20 \mu \mathrm{l}$ total reaction mixture for $\mathrm{qPCR}$ contained $20 \mathrm{ng}$ cDNA template, $10 \mu \mathrm{l}$ of $2 \mathrm{X}$ KAPA SYBR FAST qPCR master mix, $200 \mathrm{nM}$ of forward and reverse primers and PCR-grade water. $\beta$-actin was used as a reference gene. The sequences of the primers for the reaction were as follows: H-p53-F, forward 5'-GTT GGTCGGTGGGTTGGTAGTTT-3' and reverse 5'-GGTGTG GGATGGGGTGAGATTT-3'; H-c-Myc-F, forward 5'-CTT CTCTCCGTCCTCGGATTCT-3' and reverse 5'-GAAGGTGATCCAGACTCTGACCTT-3'; and $\beta$-actin, forward 5'-TGC AGAGGATGATTGCTGAC-3' and reverse 5'-GAGGAC TCCAGCCACAAAGA-3'. The reaction was performed in an Applied Biosystems 7500 Real-Time PCR System (Applied Biosystems; Thermo Fisher Scientific, Inc.) with the following PCR cycling conditions: Enzyme activation for $3 \mathrm{~min}$ at $95^{\circ} \mathrm{C}$, followed by 40 cycles of initial denaturation at $95^{\circ} \mathrm{C}$ for $30 \mathrm{sec}$ and annealing/extension at $58^{\circ} \mathrm{C}$ for $32 \mathrm{sec}$. Melting curve analysis was performed for verifying specificity of each primer 
after PCR to ensure amplification specificity. The threshold cycle number was determined and used in the comparative $\mathrm{Cq}$ method. The relative quantity of the target gene was estimated using the $2^{-\Delta \Delta C q}$ method (27). All data were analyzed using ABI 7500 v. 2.0 software (Applied Biosystems; Thermo Fisher Scientific, Inc.).

Statistical analysis. Experiments on cell viability, western blotting and RT-qPCR were repeated three times in triplicate measurement. Statistical analyses were performed with one-way analysis of variance followed by a post hoc analysis (Tukey's multiple comparison test) using GraphPad Prism v.5.0 software for Windows (GraphPad Software, Inc., La Jolla, CA, USA). The results were expressed as the mean + standard deviation for each group. $\mathrm{P}<0.05$ was considered to indicate a statistically significant difference.

\section{Results}

CCC serum concentration selection by cell viability assay. To select the optimal CCC serum concentration for the treatment, MTT assay was performed to measure cell viability of low-level differentiated BGC-823 cells and mid-level differentiated SGC-7901 cells. The results demonstrated an increase in inhibition rate as the CCC serum concentration increased from 5 to $20 \%$ in both the low-level differentiated BGC-823 cells and mid-level differentiated SGC-7901 cells (Fig. 1). Thus, $20 \%$ CCC serum was selected for usage in the following experiments.

CCC serum incubation treatment time selection by cell viability assay. To select the optimal CCC serum incubation time for the treatment, cell viability percentage of low-level differentiated BGC-823 cells and mid-level differentiated SGC-7901 cells were estimated by MTT following 24, 48 or $72 \mathrm{~h}$ exposure to $20 \% \mathrm{CCC}$ serum. The results demonstrated a similar inhibition level at 48 and $72 \mathrm{~h}$, which was higher than that at $24 \mathrm{~h}$, in BGC-832 cells. A similar inhibition level at 24 and $48 \mathrm{~h}$ was observed in the SGC-7901 cells, which was lower than that at $72 \mathrm{~h}$. All inhibition ratios were significantly increased in the CCC serum-treated groups compared with the control groups $(\mathrm{P}<0.05$; Fig. 2).

Both 20\% CCC serum and combined therapy inhibit tumorigenicity. In the BGC-823 and SGC-7901 cell lines, CCC serum therapy, 5-FU and combined therapy, which consisted of $20 \%$ CCC serum +5 -FU, demonstrated significant inhibition to cell viability $(\mathrm{P}<0.05)$ compared with the control serum group (Fig. 3). Combined therapy provided a significantly increased and stable inhibition rate of $>80 \%$ when compared with the control group over the 72 -h observation time $(\mathrm{P}<0.05)$. In both of the cell lines, combined therapy resulted in a superior inhibition rate when compared with $20 \%$ CCC serum or 5-FU treatment alone ( $\mathrm{P}<0.05$; Fig. 3).

$20 \%$ CCC serum synergistically enhances the effect of 5-FU on cell viability in gastric cancer cell lines. To examine the effect of 5-FU and 20\% CCC on cell viability and survival, low-level differentiated BGC-823 gastric cancer cells and mid-level differentiated SGC-7901 gastric cancer cells were each exposed to $20 \% \mathrm{CCC}$ serum, $5-\mathrm{FU}(10 \mu \mathrm{l} / \mathrm{ml})$ or combined therapy consisting of $20 \%$ CCC serum +5 -FU $(10 \mu \mathrm{l} / \mathrm{ml})$ for $24 \mathrm{~h}$ before cell numbers were counted for a continuous 5 days. On day 2 , cell numbers were similar between each treatment in both BGC-823 and SGC-7901. On day 3, 4 and 5 , cell numbers were significantly decreased $(\mathrm{P}<0.05)$ in the $20 \%$ CCC serum +5 -FU group when compared with control serum group in both cell lines (Fig. 4). On day 3, 4 and 5, similar inhibition effects were observed in the $20 \%$ CCC serum and 5-FU groups in both cell lines. When both CCC serum and 5-FU were incubated together with the cells, the combined treatment group cells demonstrated a significant reduction in cell number compared with separate treatment at 96 and $120 \mathrm{~h}(\mathrm{P}<0.05)$.

$20 \%$ CCC serum and 5-FU treatment induce apoptosis in gastric cancer cells. In the present study, the apoptotic rate of gastric cancer cells BGC-823 and SGC-7901 were quantified by flow cytometry assay. As demonstrated in Fig. 5A, both 20\% CCC serum and 5-FU significantly induced apoptosis in the gastric cancer cell lines compared with control serum and blank control group $(\mathrm{P}<0.05)$, and combination treatment resulted in a significantly greater increase in the apoptosis rate compared with either treatment alone $(\mathrm{P}<0.05)$.

Western blotting analysis was performed to analyze the potential mechanism involved in $20 \%$ CCC serum and 5-FU-induced apoptosis. Results demonstrated that the protein expression levels of p-JNK and p-p38 kinase were markedly decreased after treatment with CCC serum or combined therapy in the SGC-7901 cell line, and only p-p38 kinase was notably decreased in the BGC-823 cell line. Conversely, protein expression levels of PCNA, ERK1/2 and I $\kappa \mathrm{B} \alpha$ were not affected (Fig. 5B). Together, these results implied that combined therapy induced cell apoptosis through deactivation of JNK and p38 kinase pathways but demonstrated no effect on $\mathrm{I} \kappa \mathrm{B} \alpha$ and ERK phosphorylation.

Expression of apoptosis-related genes in gastric cancer cells. To observe the gene expression levels of apoptosis-related genes in low-level differentiated BGC-823 cells and mid-level differentiated SGC-7901 cells that were exposed to combination treatment with $20 \%$ CCC serum and 5-FU or each treatment alone, the gene expression levels of C-MYC and p53 were investigated using RT-qPCR analyses. mRNA expression levels of C-MYC were significantly decreased with $20 \%$ CCC serum $(\mathrm{P}<0.05)$ and $20 \% \mathrm{CCC}$ serum +5 -FU treatment $(\mathrm{P}<0.05)$ in both cell lines compared with $20 \%$ control serum treatment or cells without treatment. P53 mRNA expression levels were significantly increased in the $20 \%$ control serum group $(\mathrm{P}<0.05)$ compared with cells without treatment in BGC-823 cell line. Furthermore, significantly increased p53 mRNA expression levels were demonstrated in the $20 \%$ CCC serum $+5-\mathrm{FU}$ treatment group compared with $20 \%$ control serum, 20\% CCC serum or 5-FU treatment in BGC-823 $(\mathrm{P}<0.05)$ and SGC-7901 $(\mathrm{P}<0.05)$ cells. The present results indicated that combined therapy demonstrated the greatest significant change in C-MYC and p53 mRNA expression levels in both of the cell lines compared with cells without treatment (Fig. 6). 

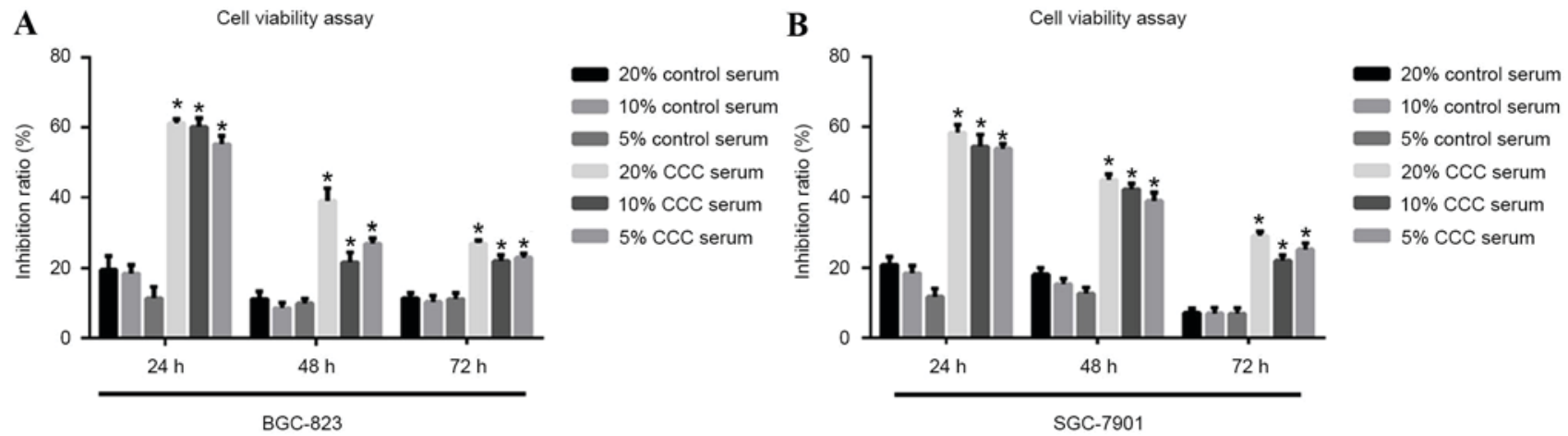

Figure 1. Inhibition rate of (A) low-level differentiated BGC-823 cells and (B) mid-level differentiated SGC-7901 cells was estimated by MTT assay following treatment with different concentrations of CCC serum. Data are presented as the mean + standard deviation of three separate experiments. "P $<0.05$ vs. the control serum at the corresponding concentration. CCC, compound cantharides capsules.
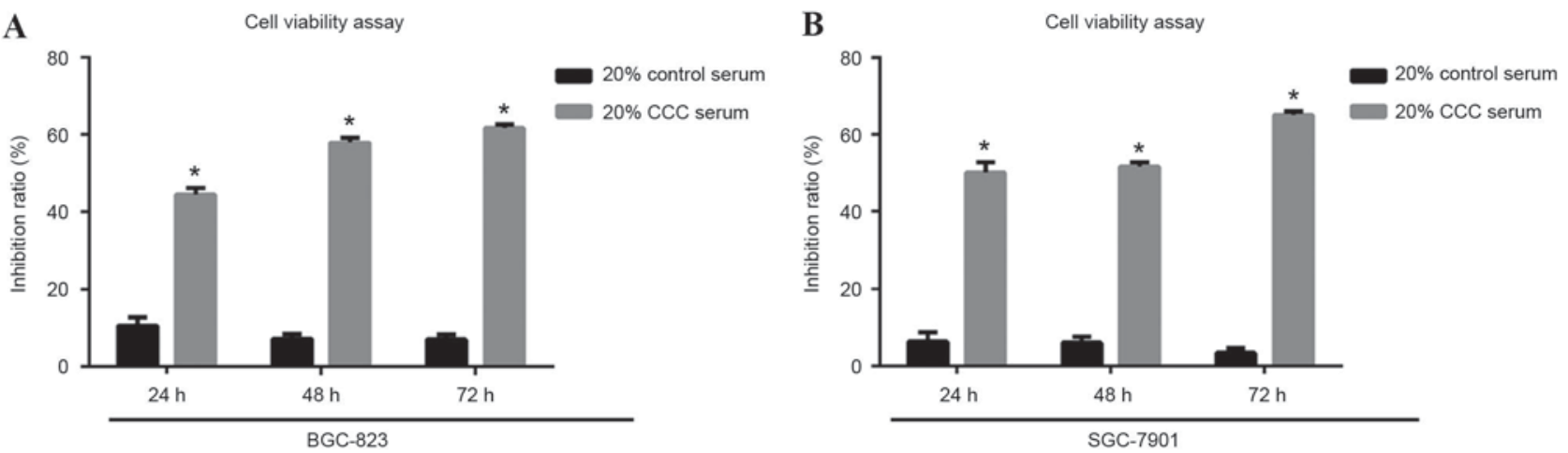

Figure 2. Inhibition rate of (A) low-level differentiated BGC-823 cells and (B) mid-level differentiated SGC-7901 cells was estimated by MTT assay following 24-, 48- or 72-h incubation with $20 \%$ CCC serum. Data are presented as the mean + standard deviation of three separate experiments. ${ }^{*} \mathrm{P}<0.05$ vs. $20 \%$ control serum in the same cell line at the same time point. CCC, compound cantharides capsule.
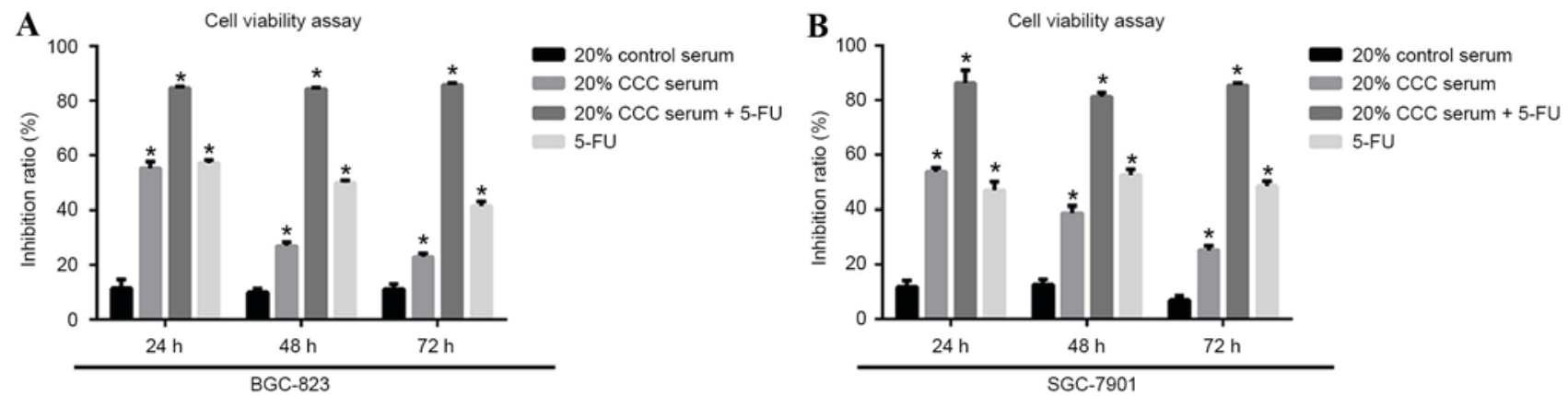

Figure 3. Inhibition rate of (A) low-level differentiated BGC-823 cells and (B) mid-level differentiated SGC-7901 cells was estimated by MTT assay following a 24-, 48- or 72-h observation period with four treatments: $20 \%$ control serum, $20 \%$ CCC serum, 5-FU or combined treatment with $20 \%$ CCC serum + 5-FU. Data are presented as the mean + standard deviation of three separate experiments. " $\mathrm{P}<0.05 \mathrm{vs}$. $20 \%$ control serum in the same cell line at the same time point. CCC, compound cantharides capsule; 5-FU, 5-fluorouracil.

\section{Discussion}

The present study indicated that CCC serum treatment reduced cell viability by inducing apoptosis in human gastric cancer cells (SGC-7901 and BGC-823). Notably, to the best of our knowledge, the present findings demonstrated, for the first time, that CCC serum treatment was able to enhance the effects of 5-FU to reduce cell viability and induce apoptosis in human gastric cancer cells. These findings suggest that cantharide may be a potential chemosensitizer for 5-FU-based chemotherapy regimens against gastric cancer.

Gastric cancer is ranked as the fourth most common type of cancer and the third leading cause of cancer mortality among men and women worldwide (1). The most common toxicities of chemotherapy or radiotherapy in the treatment of gastric cancer were leukopenia, nausea/vomiting, alopecia and proteinuria $(32,33)$. Therefore, novel therapeutic agents with reduced toxicity for patients are in high demand. In the past decades, various natural products have demonstrated to be 

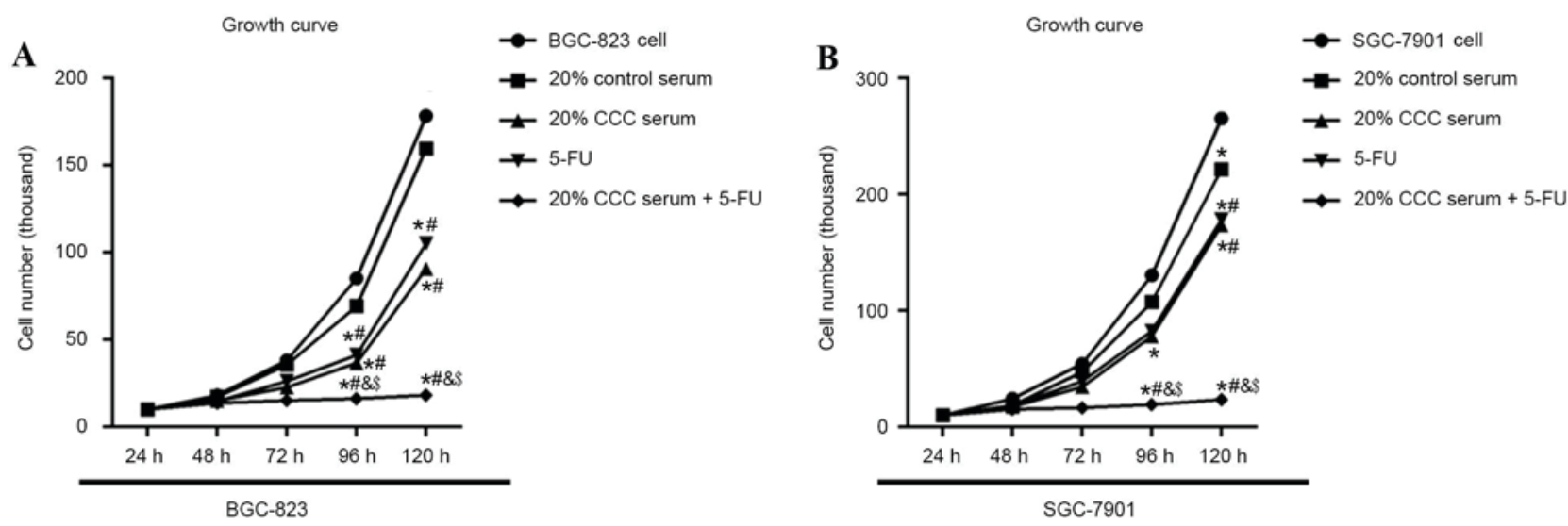

Figure 4. Effect of 20\% CCC serum and 5-FU in (A) low-level differentiated BGC-823 cells and (B) mid-level differentiated SGC-7901 cells was determined by cell growth analysis following a 5-day observation period with four treatments: $20 \%$ control serum, $20 \%$ CCC serum, 5 -FU or combined treatment with $20 \%$ CCC serum + 5-FU. ${ }^{*} \mathrm{P}<0.05$ vs. cells without treatment in the same cell line; ${ }^{*} \mathrm{P}<0.05$ vs. $20 \%$ control serum group; ${ }^{\circledR} \mathrm{P}<0.05$ vs. $20 \% \mathrm{CCC}$ serum group; ${ }^{\$} \mathrm{P}<0.05$ vs. 5-FU group. CCC, compound cantharides capsule; 5-FU, 5-fluorouracil.

BGC-823

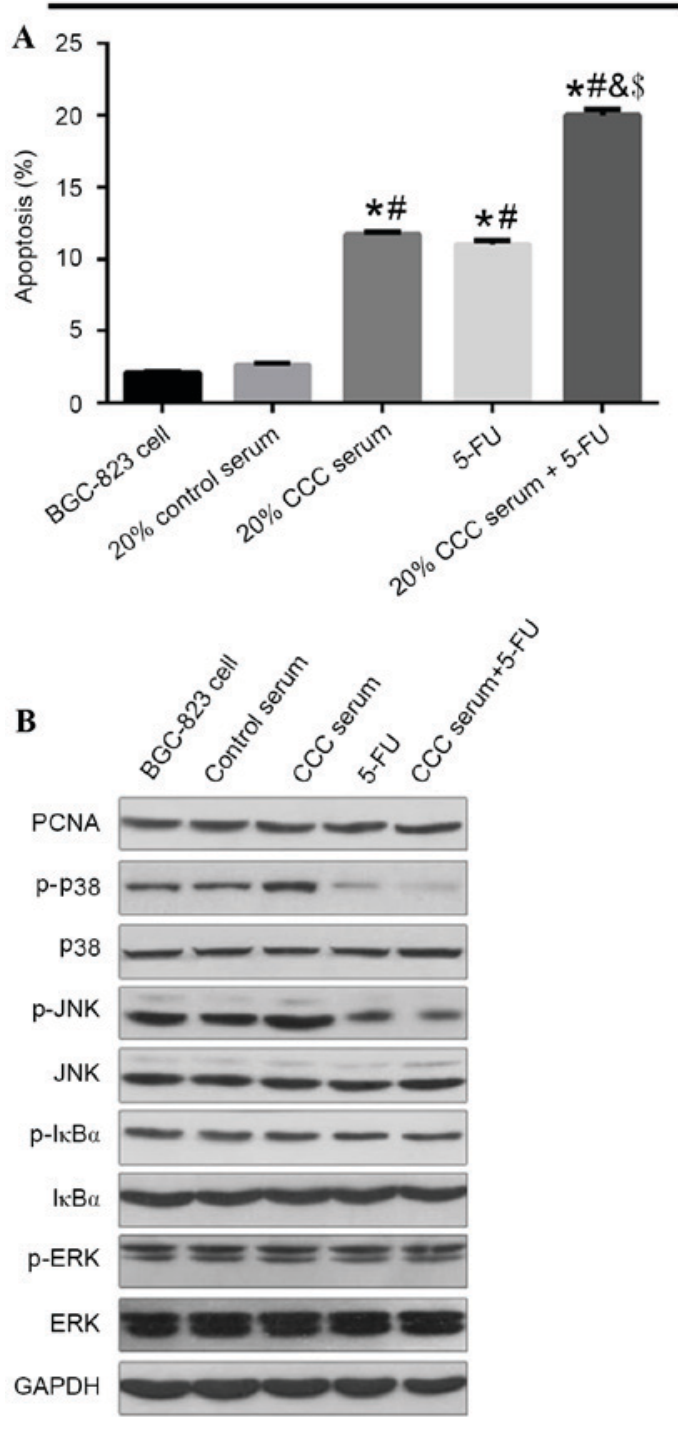

SGC-7901
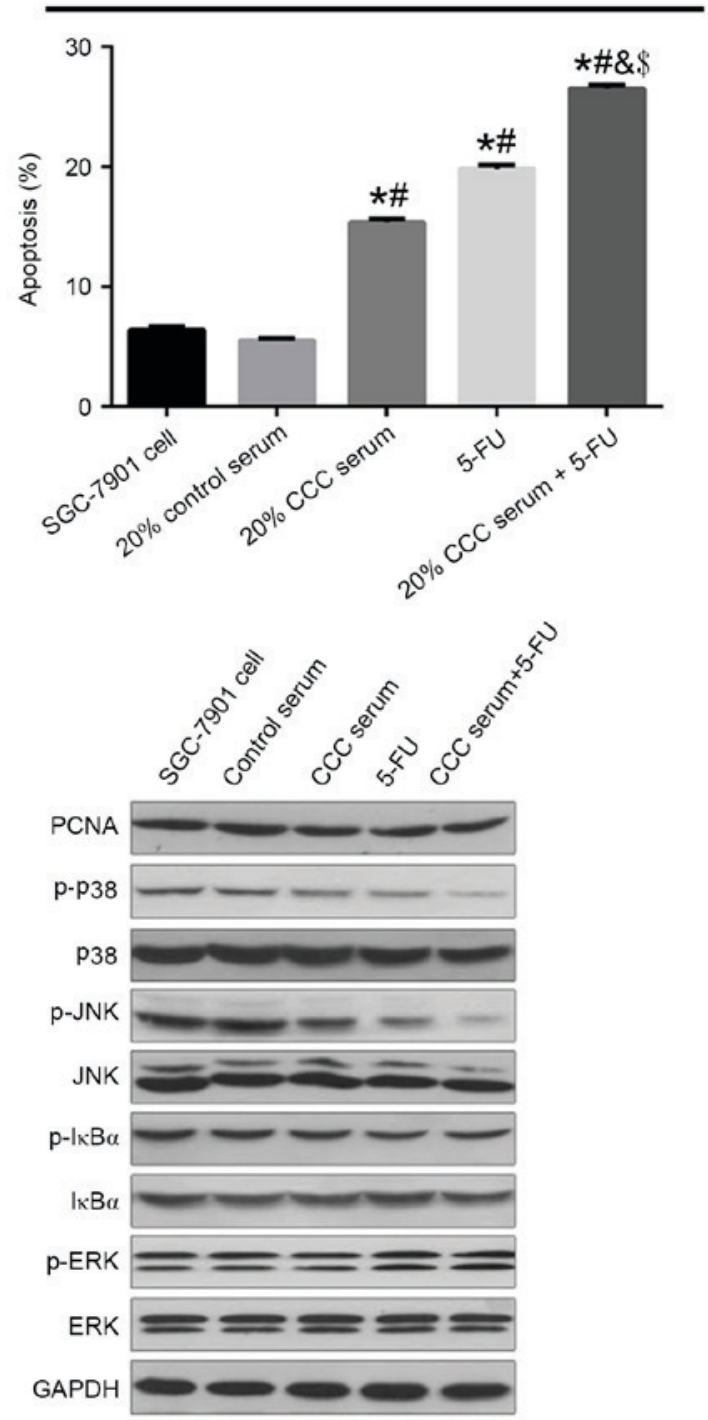

Figure 5. (A) Cell apoptotic rate was determined after combination treatment with 20\% CCC serum and 5-FU in low-level differentiated BGC-823 cells and mid-level differentiated SGC-7901 cells by flow cytometric analysis of apoptotic cells. (B) Protein expression levels of PCNA, p38, JNK, IкB $\alpha$, ERK1/2 and GAPDH in BGC-823 and SGC-7901 cells were detected by western blot analysis. Data are presented as the mean + standard deviation of three separate experiments. ${ }^{*} \mathrm{P}<0.05$ vs. cells without treatment in the same cell line; ${ }^{*} \mathrm{P}<0.05$ vs. $20 \%$ control serum group; ${ }^{\&} \mathrm{P}<0.05$ vs. $20 \% \mathrm{CCC}$ serum group; ${ }^{\$} \mathrm{P}<0.05$ vs. 5-FU group. CCC, compound cantharides capsule; 5-FU, 5-fluorouracil; PCNA, proliferating cell nuclear antigen; JNK, c-Jun N-terminal kinase; ERK, extracellular signal-related kinase; $\mathrm{p}$, phosphorylated. 
BGC-823

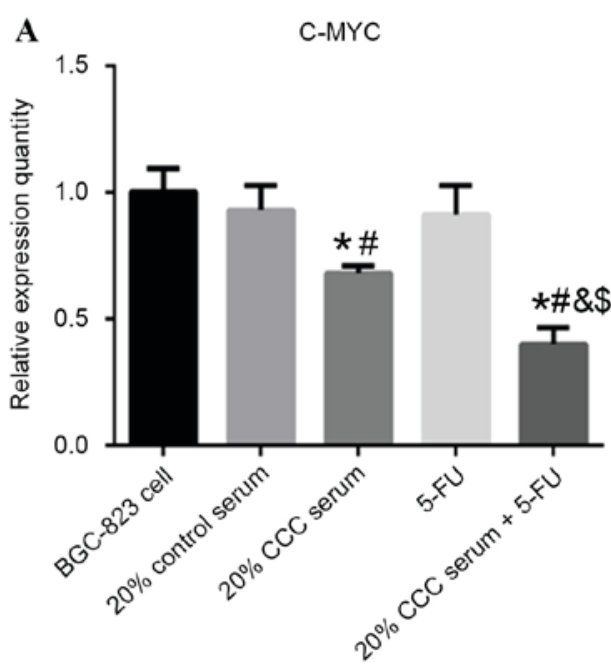

B

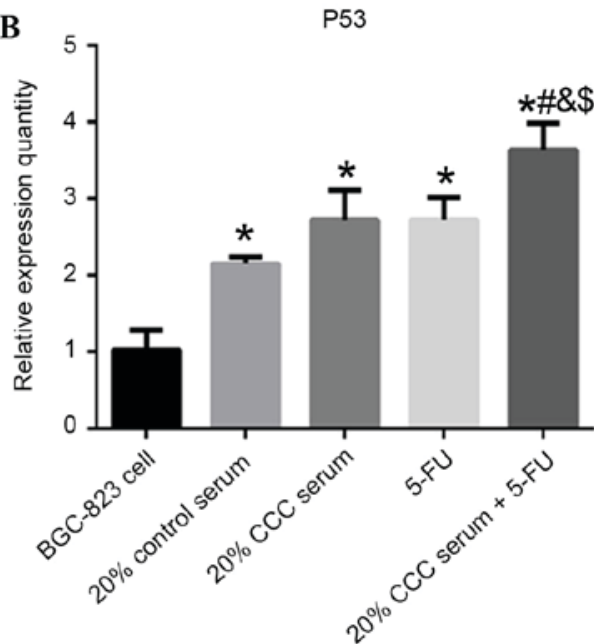

SGC-7901
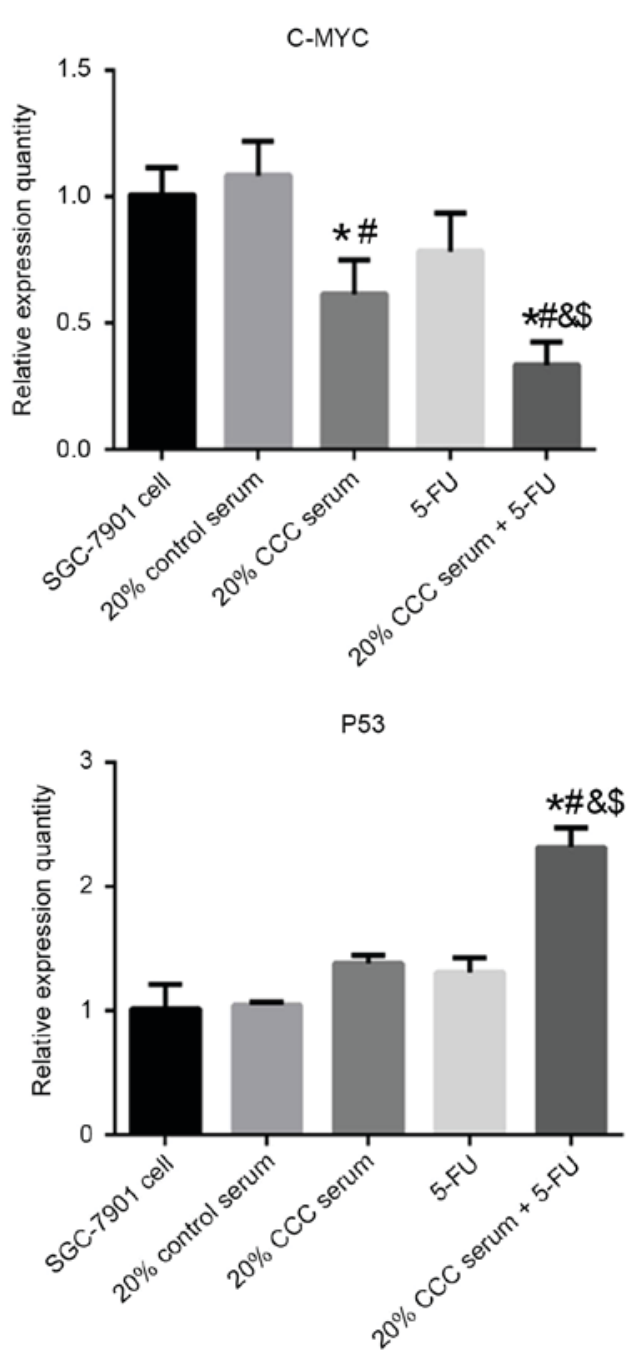

Figure 6. mRNA expression levels of (A) C-MYC and (B) p53 in low-level differentiated BGC-823 cells and mid-level differentiated SGC-7901 cells treated with CCC serum and 5-FU were determined by reverse transcription-quantitative polymerase chain reaction relative to $\beta$-actin. Data are presented as the mean + standard deviation of three separate experiments. ${ }^{*} \mathrm{P}<0.05$ vs. same cell line without treatment; ${ }^{~} \mathrm{P}<0.05$ vs. $20 \%$ control serum group; ${ }^{\&} \mathrm{P}<0.05$ vs. $20 \% \mathrm{CCC}$ serum group; ${ }^{\$} \mathrm{P}<0.05$ vs. 5 -FU group.

less toxic than anticancer agents, clinically (34). CCCs consist of a compound based on cantharides, which includes bear gallbladder powder, Panax ginseng, Astragalus mongholicus root and Eleutherococcus senticosus (35). CCCs are among numerous TCMs used for cancer treatment and have been used in clinical settings in China for various types of diseases, such as bronchial asthma, breast, liver, lung and digestive tract tumors (9). It has been demonstrated in leukemia cells that cantharides are inhibitors of protein phosphatase 1 and 2A (36). Cantharidin has been demonstrated to induce apoptosis by a p53-dependent mechanism (29). Such effects may be mediated by any of the various mechanisms in which cantharides are involved (36-41). However, studies regarding the molecular basis of the effects of cantharides in gastric cancer cell lines have been limited. Also, previous studies investigating cantharide were using cantharidin, a chemical compound, which was added into the cell culture (42). However, when orally ingesting CCCs, cantharide in the blood serum is the most effective medicine (31). To the best of our knowledge, the present study indicates for the first time that, by mimic the pharmacological change in human being, and directly adopted the blood serum after SD rats intake the capsules, which is a more direct model to study the effects of cantharide.

In the present study, the effect of cantharide in gastric cancer cells and its potential modulation were explored. A CCC serum model was established to mimic cantharide serum after human oral intake. Previous studies have demonstrated that cantharide induces apoptosis in colon cancer, human hepatoma, oral buccal carcinoma and liver carcinoma cells in vitro $(37,43,44)$. Therefore, we speculated that cantharide, a potent inhibitor of cancer cell proliferation, also has antitumor effects on human gastric cancer cells. It was demonstrated that cantharide had inhibitory effects on gastric cancer cell viability and induced apoptosis in gastric cancer cells. The inhibition level of cells from the 20\% CCC serum group was not as high as the cells that underwent 5-FU treatment. Combined therapy indicated the strongest inhibition effect in human gastric cancer cells, demonstrating a strong clinical potential for adopting CCC 
in chemotherapy to enhance 5-FU effects. The cell viability interruption of gastric cancer cells in the five groups revealed that 20\% CCC exhibited a similar effect to 5-FU. However, cell growth was significantly reduced following combined therapy treatment compared with 5-FU or CCC serum alone, which indicated a mutual promotion between $\mathrm{CCC}$ and 5-FU.

In addition, previous reports have suggested that cantharide induced apoptosis via p38, MAPK and JNK activation in pancreatic cancer and leukemia cells $(29,45)$. Consistent with the previous studies, the present results indicated that the protein expression levels of p-p38 and p-JNK were also increased through CCC treatment in gastric cancer cells; however, the MAPK-associated factors, IkB $\alpha$ and ERK, were not activated. These findings differ from a previous report in U937 human myelocytic leukemic cells (29), which indicated that cantharidin may not activate all MAPK pathways during human gastric cancer cell apoptosis and viability inhibition. The phosphorylation of p53 at serine 15 was reported to be a key phosphorylation target during the $\mathrm{p} 53$ activation process in apoptosis $(25,46)$. There has not yet been evidence to correlate phosphorylation and 553 by ERK1/2, and in the present study, the relationship between ERK-1/2 and p53 was not fully clarified. Overall, the present findings suggested that cantharidin is able to induce apoptosis by increased the expression of the p-p38 and p-JNK associated with C-MYC and p53.

In conclusion, to the best of our knowledge, the present study reported, for the first time, that the administration of CCCs, an effective serum containing cantharide, induces apoptosis to varying degrees in differentiated gastric cells. Furthermore, CCCs were able to promote 5-FU chemotherapy effects as a combined therapy and inhibit the cell viability of gastric cancer cells. Additionally, CCC administration promoted downregulation of c-Myc and upregulation of p53 gene expression levels. These findings suggested that downregulation of JNK and p38 kinase signaling pathways have an important role in cantharide-induced apoptosis in human gastric cancer cells. Therefore, CCCs may be promising candidates for effective therapy to treat gastric cancer.

\section{References}

1. Jemal A, Bray F, Center MM, Ferlay J, Ward E and Forman D: Global cancer statistics, 2012. CA Cancer J Clin 61: 69-90, 2011.

2. Jemal A, Siegel R, Xu J and Ward E: Cancer statistics, 2010. Ca Cancer J Clin 60: 277-300, 2010.

3. Yang L: Incidence and mortality of gastric cancer in China. World J Gastroenterol 12: 17-20, 2006.

4. Ychou M, Boige V, Pignon JP, Conroy T, Bouché O, Lebreton G, Ducourtieux M, Bedenne L, Fabre JM, Saint-Aubert B, et al: Perioperative chemotherapy compared with surgery alone for resectable gastroesophageal adenocarcinoma: An FNCLCC and FFCD multicenter phase III trial. J Clin Oncol 29: 1715-1721, 2011.

5. Wu Y, Qi Y, Liu H, Wang X, Zhu H and Wang Z: AMPK activator AICAR promotes 5-FU-induced apoptosis in gastric cancer cells. Mol Cell Biochem 411: 299-305, 2016.

6. Camacho LH, Garcia S, Panchal AM, Lim J, Hong DS, Ng C, Madoff DC, Fu S, Gayed I and Kurzrock R: Exploratory study of hepatic arterial infusion oxaliplatin with systemic 5-fluorouracil/bevacizumab in patients with refractory solid tumor and extensive liver metastases. Clin Colorectal Cancer 9: 311-314, 2010.

7. Liu MN, Liu AY, Pei FH, Ma X, Fan YJ, DU YJ and Liu BR: Functional mechanism of the enhancement of 5-fluorouracil sensitivity by TUSC4 in colon cancer cells. Oncol Lett 10: 3682-3688, 2015.
8. He Q, Ma L, Li Y and Li G: A pilot study of an individualized comprehensive treatment for advanced gastric cancer with para-aortic lymph node metastasis. BMC Gastroenterol 16: 8, 2016.

9. Xun L, Yang G, Li X, Zhang Y, Yang J, Chang J, Sun X, Zhou X, Guo Y, Xu Y, et al: Traditional Chinese medicine in cancer care: A review of controlled clinical studies published in Chinese. PLoS One 8: e60338, 2013.

10. Éwe GE: Chinese cantharides (mylabris Cichorii). A worthy candidate for admission to the u. s. p. J Pharm Sci 9: 257-263, 1920.

11. Wang GS: Medical uses of mylabris in ancient China and recent studies. J Ethnopharmacol 26: 147-162, 1989.

12. Jia JM, Wang ZQ, Wu LJ and Wu YL: Advance of pharmacological study on ginsenoside Rb_1. Zhongguo Zhong Yao Za Zhi 33: 1371-1377, 2008 (In Chinese).

13. Li W, Zhao H, Qian W, Li H, Zhang L, Ye Z, Zhang G, Xia M, Li J, Gao J, et al: Chemotherapy for gastric cancer by finely tailoring anti-Her2 anchored dual targeting immunomicelles. Biomaterials 33: 5349-5462, 2012.

14. Han JJ, Yu JM, Wu HY, Liu JB, Song B and Xue DW: Inhibitory effect of compound cantharides capsule on the proliferation of xenografts of human hepatocellular carcinoma HepG (2)215 in mice. Zhonghua Zhong Liu Za Zhi 34: 821-825, 2012 (In Chinese).

15. Tamura G: Alterations of tumor suppressor and tumor-related genes in the development and progression of gastric cancer. World J Gastroenterol 12: 192-198, 2006.

16. Otani K,Li X, Arakawa T, Chan FK and Yu J: Epigenetic-mediated tumor suppressor genes as diagnostic or prognostic biomarkers in gastric cancer. Expert Rev Mol Diagn 13: 445-455, 2013.

17. Lee EY and Muller WJ: Oncogenes and tumor suppressor genes. Cold Spring Harb Perspect Biol 10: a003236, 1997.

18. Krautheim A, Brechlin P, Becker K, Winkler M and Steinfelder HJ: Hamster pancreatic beta cell lines with altered sensitivity towards apoptotic signalling by phosphatase inhibitors. Br J Pharmacol 129: 687-694, 2000.

19. Clarke PR, Hoffmann I, Draetta G and Karsenti E: Dephosphorylation of cdc25-C by a type-2A protein phosphatase: Specific regulation during the cell cycle in Xenopus egg extracts. Mol Biol Cell 4: 397-411, 1993.

20. Taylor BK, Stoops TD and Everett AD: Protein phosphatase inhibitors arrest cell cycle and reduce branching morphogenesis in fetal rat lung cultures. Am J Physiol Lung Cell Mol Physiol 278: L1062-L1070, 2000.

21. Shimizu S, Narita M and Tsujimoto Y: Bcl-2 family proteins regulate the release of apoptogenic cytochrome c by the mitochondrial channel VDAC. Nature 399: 483-487, 1999.

22. Schuler M, Bossy-Wetzel E, Goldstein JC, Fitzgerald P and Green DR: p53 induces apoptosis by caspase activation through mitochondrial cytochrome c release. J Biol Chem 275: 7337-7342, 2000.

23. Marchenko ND, Zaika A and Moll UM: Death Signal-induced localization of p53 protein to mitochondria a potential role in apoptotic signaling. J Biol Chem 275: 16202-16212, 2000.

24. Pflaum J, Schlosser S and Müller M: p53 family and cellular stress responses in cancer. Front Oncol 4: 285, 2014.

25. Taylor CA, Zheng Q, Liu Z and Thompson JE: Role of p38 and JNK MAPK signaling pathways and tumor suppressor p53 on induction of apoptosis in response to Ad-eIF5A1 in A549 lung cancer cells. Mol Cancer 12: 35, 2013.

26. Weilbacher A, Gutekunst M, Oren M, Aulitzky WE and van der kuip H: RITA can induce cell death in p53-defective cells independently of p53 function via activation of JNK/SAPK and p38. Cell Death Dis 5: e1318, 2014

27. Wagner EF and Nebreda ÁR: Signal integration by JNK and p38 MAPK pathways in cancer development. Nat Rev Cancer 9: 537-549, 2009

28. Sui X, Kong N, Ye L, Han W, Zhou J, Zhang Q, He C and Pan H: p38 and JNK MAPK pathways control the balance of apoptosis and autophagy in response to chemotherapeutic agents. Cancer Lett 344: 174-179, 2014

29. Huh JE, Kang KS, Chae C, Kim HM, Ahn KS and Kim SH: Roles of $\mathrm{p} 38$ and JNK mitogen-activated protein kinase pathways during cantharidin-induced apoptosis in U937 cells. Biochem Pharmacol 67: 1811-1818, 2004.

30. Shou LM, Zhang QY, Li W, Xie X, Chen K, Lian L, Li ZY, Gong FR, Dai KS, Mao YX and Tao M: Cantharidin and norcantharidin inhibit the ability of MCF-7 cells to adhere to platelets via protein kinase $\mathrm{C}$ pathway-dependent downregulation of $\alpha 2$ integrin. Oncol Rep 30: 1059-1066, 2013. 
31. Huang $\mathrm{K}$ and Ma W: Clinical observation on the patients with advanced esophageal cancer treated by chemotherapy combined with compound cantharides capsule. Zhongliu Jichu Yu Linchuang, 2014 (In Chinese).

32. Poon M, Hwang J, Dennis K, DeAngelis C, Zhang L, Chung H, Stinson J, Wong S, Pulenzas N and Chow E: A novel prospective descriptive analysis of nausea and vomiting among patients receiving gastrointestinal radiation therapy. Supportive Care Cancer 24: 1545-1561, 2016.

33. Huang J, Zhao Y, Xu Y, Zhu Y, Huang J, Liu Y, Zhao L, Li Z, Liu H, Wang QL and Qi X: Comparative effectiveness and safety between oxaliplatin-based and cisplatin-based therapy in advanced gastric cancer: A meta-analysis of randomized controlled trials. Oncotarget 7: 34824-34831, 2016.

34. Mann J: Natural products in cancer chemotherapy: Past, present and future. Nat Rev Cancer 2: 143-148, 2002.

35. Ledermann DW: Simon Bolivar and the cantharides. Rev Chilena Infectol 24: 409-412, 2007 (In Spanish).

36. Efferth T, Rauh R, Kahl S, Tomicic M, Böchzelt H, Tome ME, Briehl MM, Bauer R and Kaina B: Molecular modes of action of cantharidin in tumor cells. Biochem Pharmacol 69: 811-818, 2005.

37. Liu D and Chen Z: The effects of cantharidin and cantharidin derivates on tumour cells. Anticancer Agents Med Chem 9: 392-396, 2009.

38. Efferth T, Li PC, Konkimalla VS and Kaina B: From traditional Chinese medicine to rational cancer therapy. Trends Mol Med 13: 353-361, 2007.

39. Kadioglu O, Kermani NS, Kelter G, Schumacher U, Fiebig HH, Greten HJ and Efferth T: Pharmacogenomics of cantharidin in tumor cells. Biochem Pharmacol 87: 399-409, 2014.
40. Zhang $\mathrm{H}$ and Yan $\mathrm{X}$ : Cantharidin modulates the E2F1/MCM7-miR-106b-93/p21-PTEN signaling axis in MCF-7 breast cancer cells. Oncol Lett 10: 2849-2855, 2015.

41. Sagawa M, Nakazato T, Uchida H, Ikeda Y and Kizaki M: Cantharidin induces apoptosis of human multiple myeloma cells via inhibition of the JAK/STAT pathway. Cancer Sci 99: 1820-1826, 2008

42. Kok SH, Chui CH, Lam WS, Chen J, Lau FY, Cheng GY, Wong RS, Lai PP, Leung TW, Tang JC and Chan AS: Apoptotic activity of a novel synthetic cantharidin analogue on hepatoma cell lines. Int J Mol Med 17: 945-949, 2006.

43. Chen YN, Chen JC, Yin SC, Wang GS, Tsauer W, Hsu SF and Hsu SL: Effector mechanisms of norcantharidin-induced mitotic arrest and apoptosis in human hepatoma cells. Int J Cancer 100: $158-165,2002$.

44. Kok SH, Cheng SJ, Hong CY, Lee JJ, Lin SK, Kuo YS, Chiang CP and Kuo MY: Norcantharidin-induced apoptosis in oral cancer cells is associated with an increase of proapoptotic to antiapoptotic protein ratio. Cancer Lett 217: 43-52, 2005.

45. Li W, Xie L, Chen Z, Zhu Y, Sun Y, Miao Y, Xu Z and Han X: Cantharidin, a potent and selective PP2A inhibitor, induces an oxidative stress-independent growth inhibition of pancreatic cancer cells through G2/M cell-cycle arrest and apoptosis. Cancer Sci 101: 1226-1233, 2010.

46. Amaral JD, Xavier JM, Steer CJ and Rodrigues CM: The role of p53 in apoptosis. Discov Med 9: 145-152, 2010. 